\title{
Field Evaluation of the System Identification Approach for Tension Estimation of External Tendons
}

\author{
Myung-Hyun Noh, Taek-Ryong Seong, and Kyu-Sik Park \\ Steel Solution Center, POSCO, 100 Songdogwahak-ro, Yeonsu-gu, Incheon 406-840, Republic of Korea \\ Correspondence should be addressed to Kyu-Sik Park; kyusik.park@posco.com
}

Received 24 September 2014; Accepted 24 November 2014

Academic Editor: Guillermo Rus

Copyright (C) 2015 Myung-Hyun Noh et al. This is an open access article distributed under the Creative Commons Attribution License, which permits unrestricted use, distribution, and reproduction in any medium, provided the original work is properly cited.

\begin{abstract}
Various types of external tendons are considered to verify the applicability of tension estimation method based on the finite element model with system identification technique. The proposed method is applied to estimate the tension of benchmark numerical example, model structure, and field structure. The numerical and experimental results show that the existing methods such as taut string theory and linear regression method show large error in the estimated tension when the condition of external tendon is different with the basic assumption used during the derivation of relationship between tension and natural frequency. However, the proposed method gives reasonable results for all of the considered external tendons in this study. Furthermore, the proposed method can evaluate the accuracy of estimated tension indirectly by comparing the measured and calculated natural frequencies. Therefore, the proposed method can be effectively used for field application of various types of external tendons.
\end{abstract}

\section{Introduction}

Many structures use external tendons including the main and hanger cables for suspension bridges as well as the main cables for cable-stayed bridges, stranded cables, external reinforcing cables. External tendons use the tensile force applied to the cable, and it is used as the main or submembers for many structures. The tensile force of the external tendon applied during the construction phase varies over time after completion depending on various factors. Therefore, to estimate the tensile force of the external tendon is of a paramount importance in terms of the stability and maintenance of a structure. The most accurate means to estimate the tension on the cables is to use load cells to collect the data directly. However, this is not an option in many cases due to the conditions in the field and the higher price of the cells and short service lives of these components, which can be a maintenance challenge when malfunctions occur. Therefore, the most commonly used method is to extract the natural frequency from the acceleration signal measures and enter the data into an equation that shows the relationship between the natural frequency and tension, to estimate the tension indirectly.
The two most widely used methods are the taut string theory [1] which does not take the bending stiffness into consideration and the linear regression method [2-4] which regards the cable as a beam under the axial load and considers the bending stiffness. The estimation methods for tension using the existing dynamic method put the natural frequency values to the equation on the natural frequency and tension. Therefore, if the mathematical model used differs significantly from the actual structure, a significant error is unavoidable.

The method of estimating the tensile force of external tendons we introduce in this paper has the following two outstanding characteristics. First, since it uses the finite element model, it can be applied to any form of external tendon because when the structure is geometrically complex and difficult to determine the value of a mathematical model, the finite element model is the most effective alternative. That is, the natural frequencies of the structure can be calculated using the finite element model but not analytical methods. Second, when the number of variables to be identified is large, the methods to minimize the error between the calculated natural frequency and the measured natural frequency involve a lot of computation. For this reason, we applied 


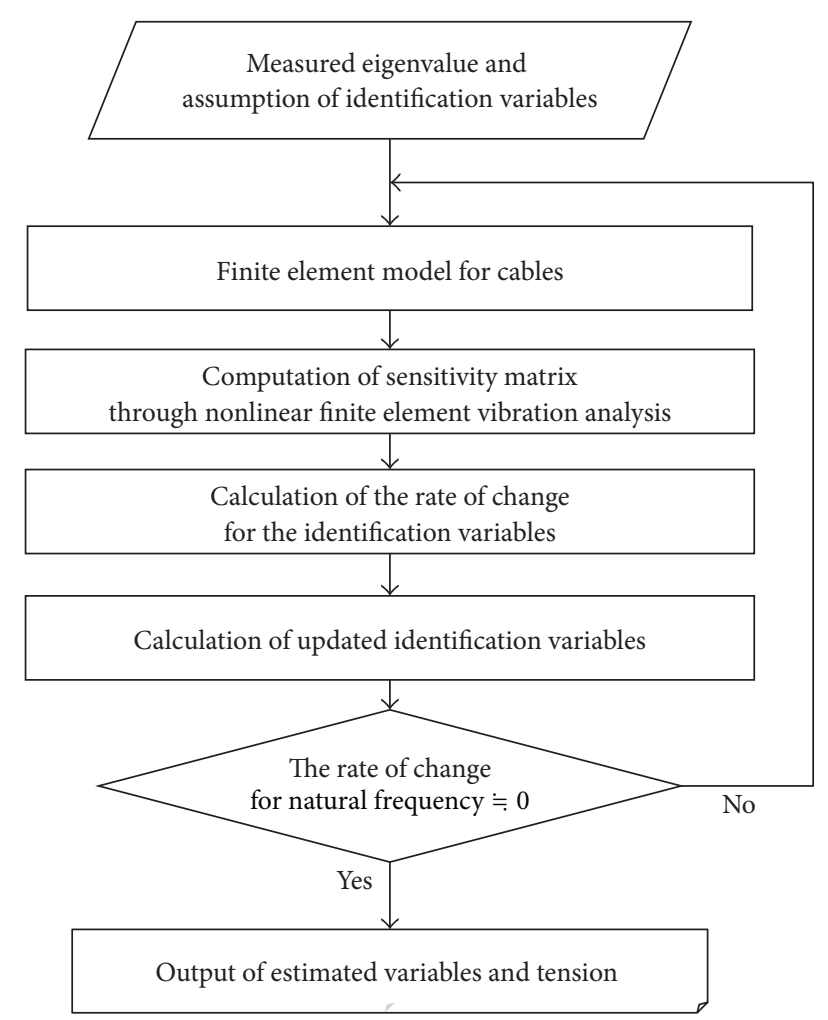

FIGURE 1: The process of estimating the tensile force using the system identification method [5].

the system identification method that uses the sensitivity analysis, which is garnering greater attention these days. The overall diagram for the process of estimating the tensile force using the system identification method is shown in Figure 1, and further details can be found in the studies by Park and Kim [5] and Park et al. [6]. In this study, the theoretical formulation of tension estimation is carried out through the system identification technique that uses the sensitivity updating algorithm, which is then applied to the benchmark numerical examples, laboratory test samples, and the field structures to verify the effectiveness of our method.

\section{Theoretical Formulation}

In the process of estimating the tension using the system identification approach based on the finite element model, the tension of external tendons is illustrated by the identification vector which is composed of several unknown parameters. The identification vector containing unknown parameters $x^{p}$ $(p=1, \ldots, m)$ used for identifying the tensile force in the system identification procedure can be defined as

$$
\mathbf{x}=\left[\begin{array}{llll}
x^{1} & x^{2} & \cdots & x^{k}
\end{array}\right]^{\mathrm{T}},
$$

where $x^{1}, x^{2}, \ldots, x^{k}$ denote the identification variables for estimating tensile force. For example, the $x^{k}$ could be set to the tension or other physical property for external tendons, that is, need to identify.
The identification vector for the $r$ th iteration in the sensitivity-based updating algorithm can be assumed as

$$
{ }^{r} \mathbf{x}=\left[\begin{array}{lllll}
{ }^{r} x^{1} & { }^{r} x^{2} & \ldots & { }^{r} x^{k}
\end{array}\right]^{\mathrm{T}},
$$

where ${ }^{r} x^{1},{ }^{r} x^{2}, \ldots,{ }^{r} x^{k}$ mean the identification variables for the $r$ th iteration.

Then, the static displacement and tendon force distribution can be produced for the identification vector. In the next step, the natural frequency $\omega_{j}(j=1, \ldots, q)$ is determined from the finite element vibration analysis using the static displacement curve and tendon force distribution. Using the change in natural frequencies for different identification variables, the sensitivity matrix $(\mathbf{S})$ with $(q \times p)$ size can be determined approximately as follows:

$$
{ }^{r} \mathbf{S}=\left[\begin{array}{ccc}
\frac{\partial^{r} \omega_{1}}{\partial^{r} x_{1}} \frac{\partial^{r} x_{1}}{\partial^{r} \omega_{1}} & \cdots & \frac{\partial^{r} \omega_{1}}{\partial^{r} x_{p}} \frac{\partial^{r} x_{p}}{\partial^{r} \omega_{1}} \\
\vdots & \ddots & \vdots \\
\frac{\partial^{r} \omega_{q}}{\partial^{r} x_{1}} \frac{\partial^{r} x_{1}}{\partial^{r} \omega_{q}} & \cdots & \frac{\partial^{r} \omega_{q}}{\partial^{r} x_{p}} \frac{\partial^{r} x_{p}}{\partial^{r} \omega_{q}}
\end{array}\right] .
$$

Then, from the produced natural frequency data, the rate of change $\left(d^{r} \omega\right)$ for the eigenvalue can be obtained as

$$
d^{r} \boldsymbol{\omega}=\left[\begin{array}{ccc}
\frac{\omega_{1}^{m}-{ }^{r} \omega_{1}^{c}}{{ }^{r} \omega_{1}^{c}} & \cdots & \frac{\omega_{q}^{m}-{ }^{r} \omega_{q}^{c}}{{ }^{r} \omega_{q}^{c}}
\end{array}\right]^{\mathrm{T}},
$$

where $\omega_{q}^{m}$ and ${ }^{r} \omega_{q}^{c}$ denote the $q$ th mode's natural frequency measured from experiment or field test and the $q$ th mode's frequency calculated from nonlinear finite element vibration analysis using ${ }^{r} x^{p}$ in the $r$ th iteration, respectively. Equation (4) can be rewritten in the vector form as

$$
d^{r} \boldsymbol{\omega}_{(q \times 1)}={ }^{r} \mathbf{S}_{(q \times p)} d^{r} \mathbf{x}_{(p \times 1)} .
$$

Equation (5) is referred to as a linear sensitivity equation, and the rate of change for the identification vector by using (5) can be expressed as

$$
d^{r} \mathbf{x}={ }^{r} \mathbf{S}^{-1} d^{r} \boldsymbol{\omega}
$$

where ${ }^{r} \mathbf{S}^{-1}$ means the pseudoinverse matrix for ${ }^{r} \mathbf{S}$ and can be determined as

$$
{ }^{r} \mathbf{S}^{-1}=\left({ }^{r} \mathbf{S}^{\mathrm{T} r} \mathbf{S}\right)^{-1}{ }^{r} \mathbf{S}^{\mathrm{T}}
$$

Finally, the $p$ th identification variable in the $(r+1)$ th iteration can recalculated as

$$
\begin{gathered}
{ }^{r+1} x^{p}=\left(1+d^{r} x^{p}\right)^{r} x^{p} \\
{ }^{r+1} \mathbf{x}=\left[\begin{array}{llll}
{ }^{r+1} x^{1} & { }^{r+1} x^{2} & \ldots & { }^{r+1} x^{k}
\end{array}\right]^{\mathrm{T}} .
\end{gathered}
$$

From (2) to (8), the loop is repeated until the termination condition is satisfied. The convergence condition for 
$T: 50 \mathrm{kN}, m: 1.5 \mathrm{~kg} / \mathrm{m}, L: 5 \mathrm{~m}$

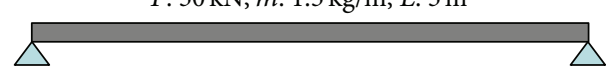

FIgURE 2: Benchmark numerical examples.

the repetition analysis uses the square roots of the sum of square (SRSS) in the following:

$$
\begin{aligned}
& \mid \sqrt{\left.\left|\sum_{q=1}^{n}\right| \frac{\omega_{q}^{m}-\omega_{q}^{c}}{\omega_{q}^{m}} \mid \times 100\right)_{\text {step } r}^{2}} \\
& -\sqrt{\left(\sum_{q=1}^{n}\left|\frac{\omega_{q}^{m}-\omega_{q}^{c}}{\omega_{q}^{m}}\right| \times 100\right)_{\text {step } r+1}^{2}} \mid<0.01 .
\end{aligned}
$$

Finally, tensile force is determined from the identification variables holding at the termination stage and relevant natural frequencies can be determined through the finite element vibration analysis with the identification variables.

To identify the mode shape number of measured natural frequency, a number of sensors are required in the system identification approach based on the finite element model.

However, few sensors (e.g., less than 4 sensors) are enough to get the required number of natural frequency with mode shape (e.g., 2 or 3 modes) in this approach. Furthermore, the sensor location can be varied when there are a limited number of sensors.

The tension estimation results will be compared with existing methods, that is, taut string theory and linear regression method and the governing equations of these two methods are shown as

$$
\begin{gathered}
T=4 m L_{e}^{2}\left(\frac{\omega_{n}}{n}\right)^{2}, \\
\left(\frac{\omega_{n}}{n}\right)^{2}=\frac{T}{4 m L_{e}^{2}}+\left(\frac{E I \pi^{2}}{4 m L_{e}^{4}}\right) n^{2},
\end{gathered}
$$

where $m, L_{e}$, and $E I$ are mass per unit length, effective length, and flexural rigidity, respectively.

\section{Benchmark Numerical Examples}

Before the field application of the tension estimation method using the system identification technique, we developed the benchmark example shown in Figure 2 to verify the development theory. In this case, the bending stiffness and boundary conditions of the cable were changed as shown in Table 1 to validate the advantages of the newly developed theory compared to existing ones.

The purpose of $\mathrm{C} 1$ and $\mathrm{C} 2$ in Table 1 is to check the influence of the bending stiffness, while C2 and C3 are to see the influence of the boundary conditions. For each of the cables, the theoretical first through third natural frequencies are shown in Table 2.

Table 3 shows the results of the tensile force estimations for the three benchmark cables using the taut string theory,

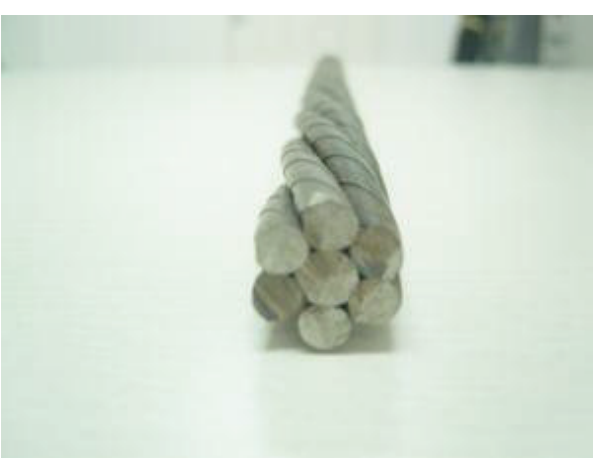

(a) No shielding

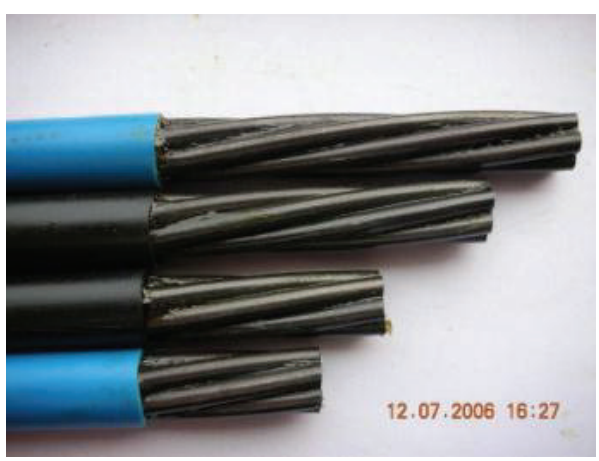

(b) Shielding

Figure 3: Seven-strand cables.

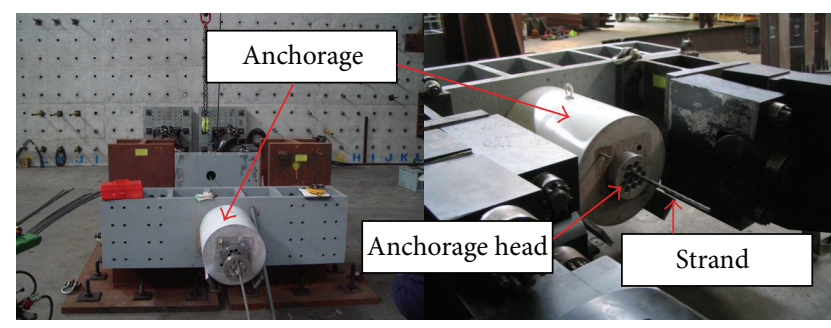

FIgURE 4: Test set-up.

TABLE 1: Variation of parameter for benchmark numerical examples.

\begin{tabular}{lcc}
\hline Cable ID & Bending stiffness $\left(\mathrm{N}-\mathrm{m}^{2}\right)$ & Boundary condition \\
\hline $\mathrm{C} 1$ & 100 & Hinged-Hinged \\
$\mathrm{C} 2$ & 1000 & Hinged-Hinged \\
$\mathrm{C} 3$ & 1000 & Fixed-Fixed \\
\hline
\end{tabular}

TABLE 2: Natural frequencies calculated from benchmark numerical examples $(\mathrm{Hz})$.

\begin{tabular}{lccc}
\hline Cable ID & 1st & 2nd & 3rd \\
\hline C1 & 18.26 & 36.57 & 54.79 \\
C2 & 18.33 & 37.09 & 56.69 \\
C3 & 19.44 & 39.33 & 60.12 \\
\hline
\end{tabular}

the linear regression method, and the newly developed method. As shown in Table 3, the taut string theory, which is in capable of considering the bending stiffness, shows the 
TABLE 3: Tension estimations error (\%) of the benchmark examples.

\begin{tabular}{|c|c|c|c|c|}
\hline Cable ID & & & Linear regression method & System identification method (this study) \\
\hline & 1st & 0.08 & & \\
\hline $\mathrm{C} 1$ & 2nd & 0.32 & 0.00 & 0.00 \\
\hline & 3rd & 0.71 & & \\
\hline & 1st & 0.08 & & \\
\hline $\mathrm{C} 2$ & 2nd & 3.16 & 0.00 & 0.00 \\
\hline & 3rd & 7.11 & & \\
\hline & 1st & 13.32 & & \\
\hline $\mathrm{C} 3$ & 2nd & 16.01 & 12.43 & 0.00 \\
\hline & $3 \mathrm{rd}$ & 20.47 & & \\
\hline
\end{tabular}

TABLE 4: Estimation error (\%) of multiple variables for the cable C2.

\begin{tabular}{lc}
\hline Identification variable & Estimation error \\
\hline$T, L$ & $T=0.02, L=0.01$ \\
$T, m$ & $T=0.13, m=0.13$ \\
$m, L$ & $m=0.04, L=0.02$ \\
$T, m, L$ & $T=0.77, m=0.00, L=0.36$ \\
\hline
\end{tabular}

TABLE 5: Applied tension and extracted natural frequencies.

\begin{tabular}{lcc}
\hline Test ID & $\begin{array}{c}\text { Applied tension } \\
\text { (ton) }\end{array}$ & $\begin{array}{c}\text { Extracted natural } \\
\text { frequencies }(\mathrm{Hz})\end{array}$ \\
\hline Test 1 & 4.05 & $21.36,42.94$ \\
Test 2 & 8.73 & $30.88,61.87,93.41$ \\
Test 3 & 13.46 & $38.07,76.35,114.80$ \\
Test 4 & 18.35 & $44.31,88.68$ \\
\hline
\end{tabular}

errors in the estimated tensile forces as the bending stiffness increases ( $\mathrm{C} 1$ to $\mathrm{C} 2$.) For tension estimations through the taut string theory and linear regression method, the boundary conditions cannot be considered, which resulted in a significant error in the $\mathrm{C} 3$ cable. Also, as the string theory has only one natural frequency, it can estimate the tensile force differently depending on the mode of natural frequency used even under the same tensile force. Therefore, when there is a difference in the natural frequency used in the field without the identification of the natural vibration mode, a big error is inevitable. On the other hand, the method of system identification considers the physical properties and boundary conditions, including bending stiffness. Therefore, the numerical example demonstrated that it is able to estimate the tensile force with precision. In addition, we used the SRSS (square root of sum of square) of the converged errors of the natural frequencies during the field application, which allowed us to indirectly verify the reliability of the estimated tensile force.

Since the tension estimation method using the system identification technique is based on the finite element model, it is possible to estimate not only the tensile force but also the effective length, unit mass, and bending stiffness. It is also capable of estimating single and multiple variables simultaneously. Table 4 shows the results of estimation of multiple variables for the cable C2 in Table 1.

Estimation of the multiple variables can reduce errors in the estimation of tensile force, as it can indirectly determine

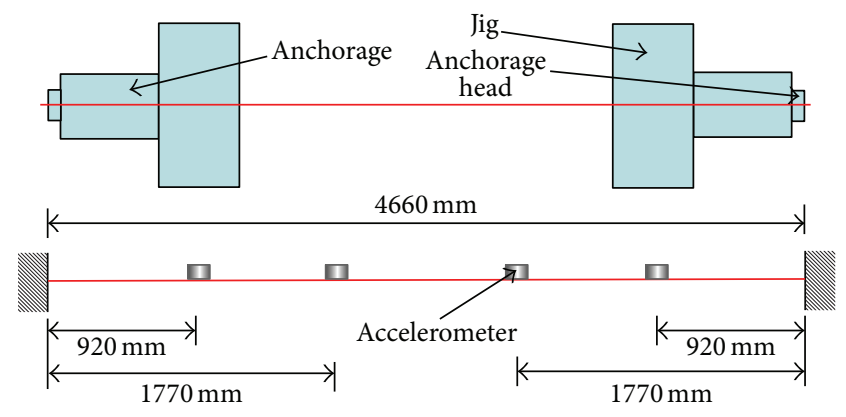

FIGURE 5: Vibration measurement set-up.

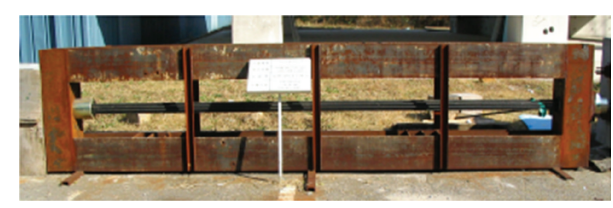

FIGURE 6: Laboratory-scale cable-stayed bridge test sample.

the variable that significantly affects the errors in estimating the tensile force (effective length, boundary conditions, and equivalent unit mass)

\section{Application to Laboratory Test Samples}

Before we applied the newly developed method that was verified by means of the benchmark numerical example, we applied this new method to two test samples to identify possible problems that might occur during field applications and complement them as necessary.

4.1. Strand Cable Test Sample. Strand cables are composed of 7 smaller wires and are usually the basic element to make PC steel strands or cables for cable stayed bridges and suspended cables. Depending on the application, some strands use additional fillers or shielding to prevent them from being corroded, as shown in Figure 3. The steel strand cable used in this study was a seven-strand cable used for PC steel strand cables, and it had no fillers or shielding.

To check the estimation effect of the tension due to the changes in tension as shown in Figure 4, we used a 3000-kN 

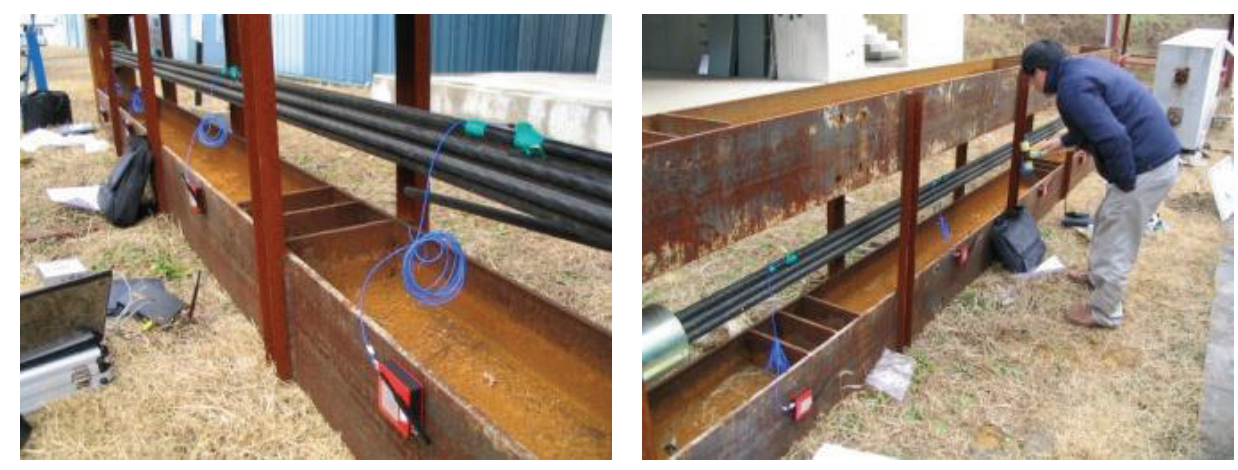

FIGURE 7: Vibration test with a laboratory-scale test sample of a cable-stayed bridge.
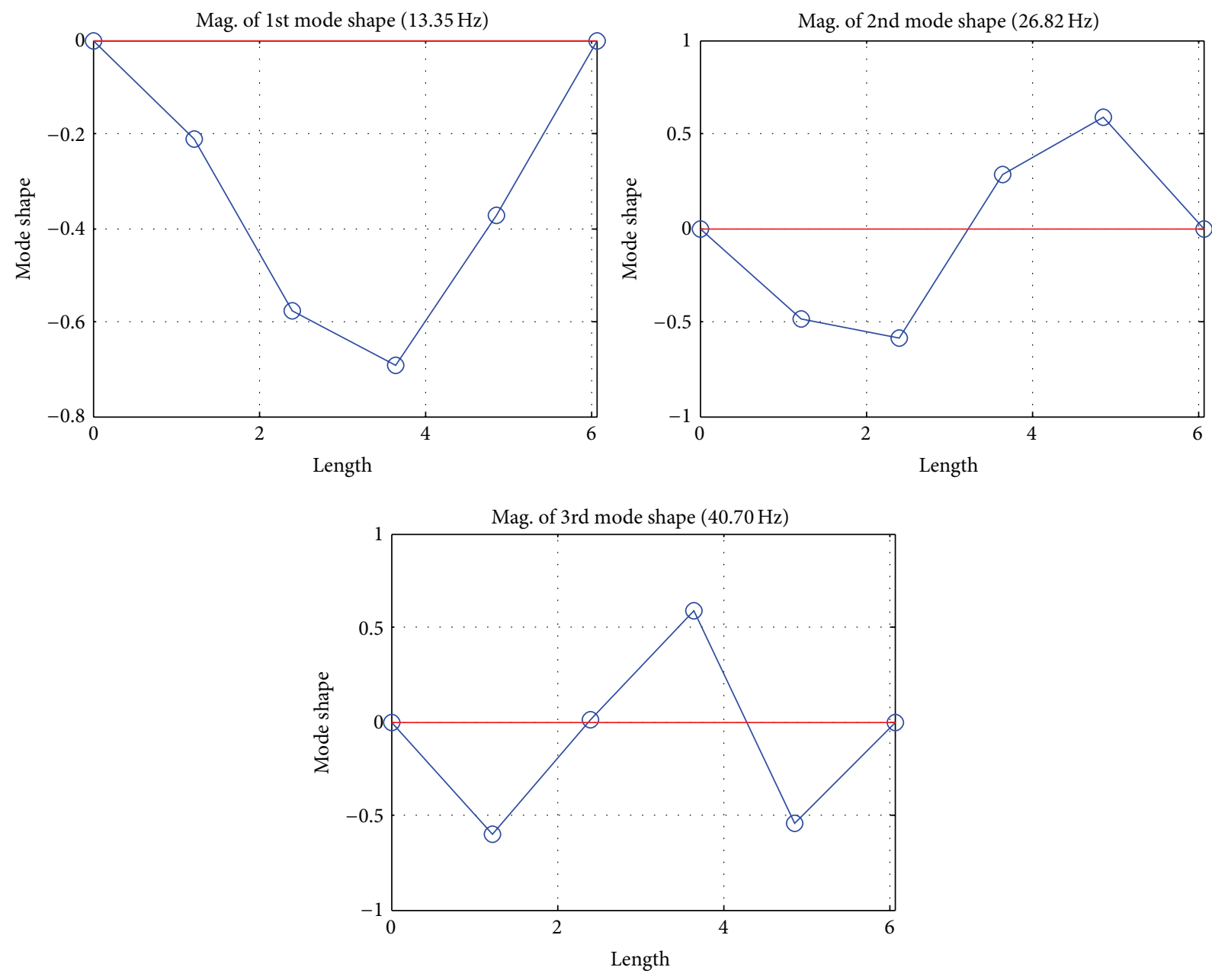

FIGURE 8: Extraction of natural vibration mode for test 1.

actuator that was located in the POSCO steel structure testing center. To measure the signals of acceleration, as shown in Figure 5, we added four accelerometers to the strand cable. The acceleration signal was transmitted to the computer through a wireless logger.

The load was applied in 4 steps. The natural frequency based on the natural vibration mode extracted from the acceleration signals are shown in Table 5. Here, tests 1 and 4 failed to identify the third natural vibration mode.

As shown in Table 6, the technique of estimating the tensile force using the system identification method turned out to have less errors in terms of tensile force estimation compared to the taut string theory or linear regression method. This is because the existing theories could not 
TABLE 6: Applied tension estimation error (\%) of strand cables.

\begin{tabular}{|c|c|c|c|c|}
\hline Test ID & \multicolumn{2}{|c|}{ Taut string theory } & Linear regression method & System identification method (this study) \\
\hline Test 1 & $\begin{array}{l}\text { 1st } \\
\text { 2nd }\end{array}$ & $\begin{array}{l}11.68 \\
12.83\end{array}$ & 11.29 & 0.70 \\
\hline Test 2 & $\begin{array}{c}\text { 1st } \\
\text { 2nd } \\
\text { 3rd }\end{array}$ & $\begin{array}{r}8.09 \\
8.48 \\
9.90\end{array}$ & 7.74 & 0.05 \\
\hline Test 3 & $\begin{array}{c}\text { 1st } \\
\text { 2nd } \\
\text { 3rd }\end{array}$ & $\begin{array}{l}6.61 \\
7.20 \\
7.72\end{array}$ & 6.56 & 0.35 \\
\hline Test 4 & $\begin{array}{l}\text { 1st } \\
\text { 2nd }\end{array}$ & $\begin{array}{l}5.92 \\
6.07\end{array}$ & 5.87 & 0.62 \\
\hline
\end{tabular}

TABLE 7: Tension estimation error (\%) of a laboratory-scale test sample of a cable-stayed bridge.

\begin{tabular}{lcccc}
\hline Test ID & \multicolumn{2}{c}{ Taut string theory } & Linear regression method & System identification method (this study) \\
\hline \multirow{2}{*}{ Test 1} & 1st & 12.95 & 12.35 & 1.49 \\
& 2nd & 13.98 & & 1.60 \\
Test 2 & 3rd & 16.59 & 12.36 & \\
& 1st & 12.95 & & 2.19 \\
Test 3 & 3rd & 14.24 & 13.44 & \\
$($ Test 4$)$ & 1st & 16.94 & & \\
& 2nd & 14.24 & & \\
\hline
\end{tabular}

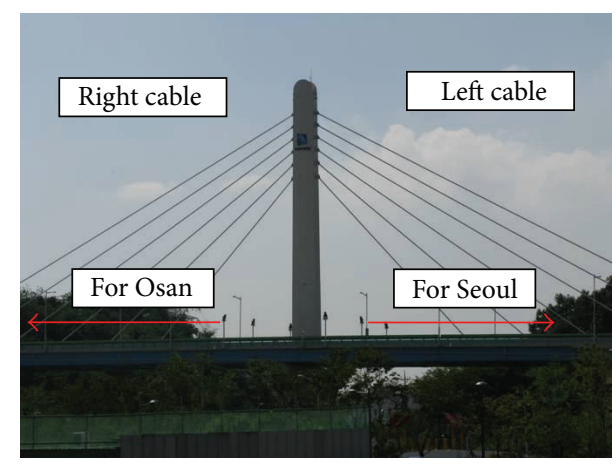

FIGURE 9: Yeongdeok number 1 cable-stayed bridge.

TABLE 8: Mean and standard deviation (\%) of tension estimation errors for stay-cable.

\begin{tabular}{lcc}
\hline Method & Mean & Standard deviation \\
\hline $\begin{array}{l}\text { Taut string theory } \\
\text { Linear regression } \\
\text { method }\end{array}$ & 4.42 & 4.59 \\
$\begin{array}{l}\text { System identification } \\
\text { method (this study) }\end{array}$ & 4.14 & 4.29 \\
\hline
\end{tabular}

consider the boundary conditions of the strand cable or the bending stiffness.

4.2. Laboratory-Scale Cable-Stayed Bridge Test Sample. In addition to the strand cable test sample, we conducted the tensile force estimation experiment with a laboratory-scale

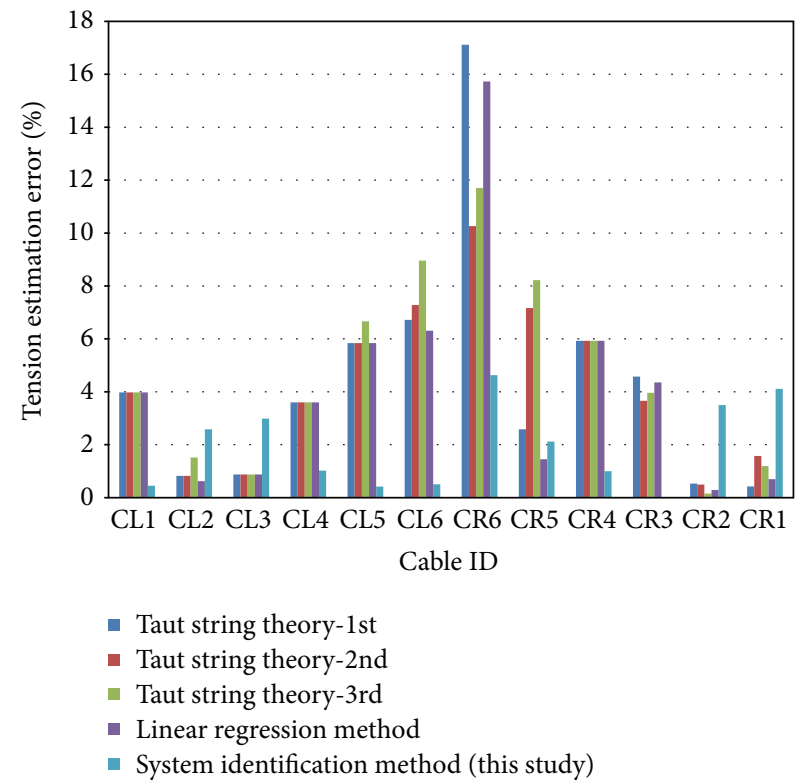

FIgURE 10: Tension estimation error (\%) of Yeongdeok number 1 stay-cable.

test sample of a cable-stayed bridge as shown in Figures 6 and 7. In this case, the cable used was shielded steel strand cable, with a tensile force of $30 \mathrm{kN}$.

To examine the influence on the estimation of the tensile force by the setup of the vibration measurement, we altered the positions of the accelerometers, the hitting point of the impact hammer, and the time of measuring the vibration, in four separate test scenarios. 


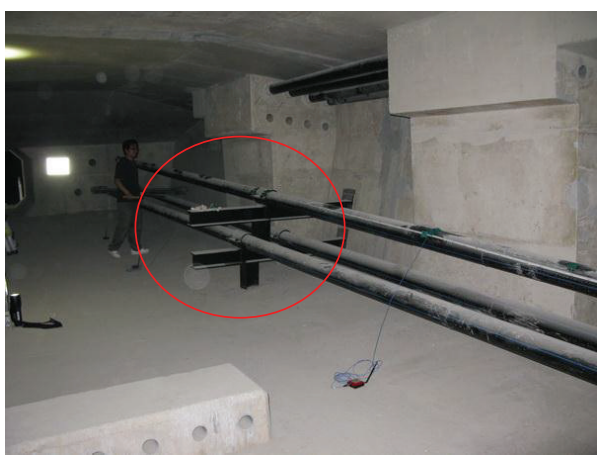

(a) Vibration preventing device

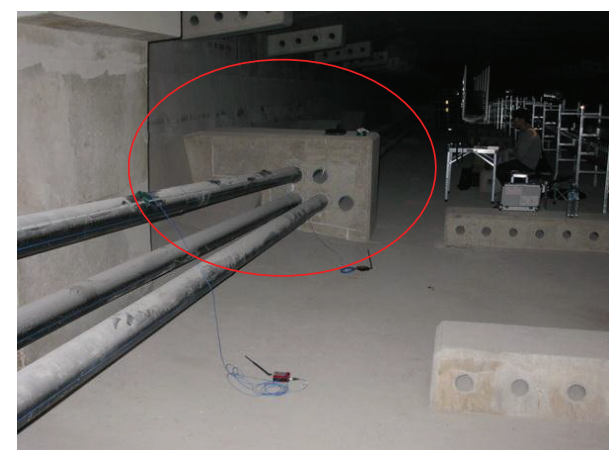

(b) Deviation block

FIGURE 11: External tendon of the approach bridge of Incheon Grand Bridge.

As carried out in the case of the strand cable test, we extracted three natural frequencies for each test. Figure 8 shows the extracted natural vibration modes for test 1 . Based on these frequencies, we estimated the tensile force as shown in Table 7, which also shows the technique for estimating the tensile force using the system identification method. This turned out to have fewer errors in terms of tensile force estimation compared to the taut string theory or the linear regression method, as with the case of steel strand cables.

\section{Field Application}

We verified the feasibility of the system identification method, which was verified by the tests with laboratory-scale test samples, by estimating the tensile forces in the field.

5.1. Stay-Cable of Yeongdeok Number 1 Bridge. The first test in the field was conducted with the cables in a cable-stayed bridge, for which the tension estimations in the field were being performed using existing theories (string theory, linear regression). Yeongdeok number 1 Bridge is a cable-stayed bridge located in Giheung district, Youngin-si, Gyounggi-do. This bridge uses PPWS (prefabricated parallel wire strands) cables.

We estimated the tensile forces of 12 cables on both sides of the bridge as shown in Figure 9 and compared the estimation results from the existing methods and new method. Figure 10 shows that the force estimation made by the system identification method has errors not exceeding $5 \%$. However, the existing methods, in some cases, showed a high level of errors. However, the methods of estimating the tensile force using the existing theories also yielded relatively desirable outcomes. This is because the length of cable stays of the bridge is within a range from $44 \mathrm{~m}$ to $95 \mathrm{~m}$, which is relatively long and similar to the assumptions used in the existing theories.

The tension estimation method using the system identification shown in Table 8 has a relatively smaller standard deviation for the estimation errors compared to those of the existing theories. Therefore, the tensile forces are able to be estimated with more reliability.
TABle 9: Mean and standard deviation (\%) of tension estimation errors for external tendon.

\begin{tabular}{lcc}
\hline Method & Mean & Standard deviation \\
\hline $\begin{array}{l}\text { Taut string theory } \\
\text { Linear regression } \\
\text { method }\end{array}$ & 18.60 & 7.61 \\
$\begin{array}{l}\text { System identification } \\
\text { method (this study) }\end{array}$ & 11.13 & 4.19 \\
\hline
\end{tabular}

5.2. External Tendon for the Approach Bridge Section of Incheon Grand Bridge. The external tendon for normal bridges is applied during the construction phase or afterwards for reinforcing the structure. To check the applicability of the system identification method for such external tendons, we applied this method to the external tendons of the approach bridge section of the Incheon Grand Bridge. The external tendons, unlike cables in cable-stayed or suspension bridges, installed deviation blocks, or vibration preventing device between the external tendons, as shown in Figure 11. Also, the external tendon was shielded in HDPE pipes and the interior was filled with mortar to prevent corrosion. Therefore, it was difficult to apply the existing theories, and there is no other way used in the field to examine the tension except load cells.

Figure 12 and Table 9 show that existing theories show significant errors with the external tendon, which is unlike the cases in the cable stays in the Yeongdeok Bridge number 1. This is because the external tendon differs significantly in many aspects of the assumptions. The tension estimation technique using the system identification method showed increased errors from the level in Yeongdeok Bridge. Still, however, the range of errors did not exceed 5\%.

5.3. Extradosed Cable for Aam Bridge. Aam Bridge of Figure 13 constructed in the approach sector of the Incheon Grand Bridge. It was built as an extradosed bridge, which is similar to a cable stayed bridge and uses MS (multistrand) cables that are shielded in HDPE pipes. There is no separate grouting inside the cable. Figure 14 shows the vibration measurement set-up of an extradosed cable. 


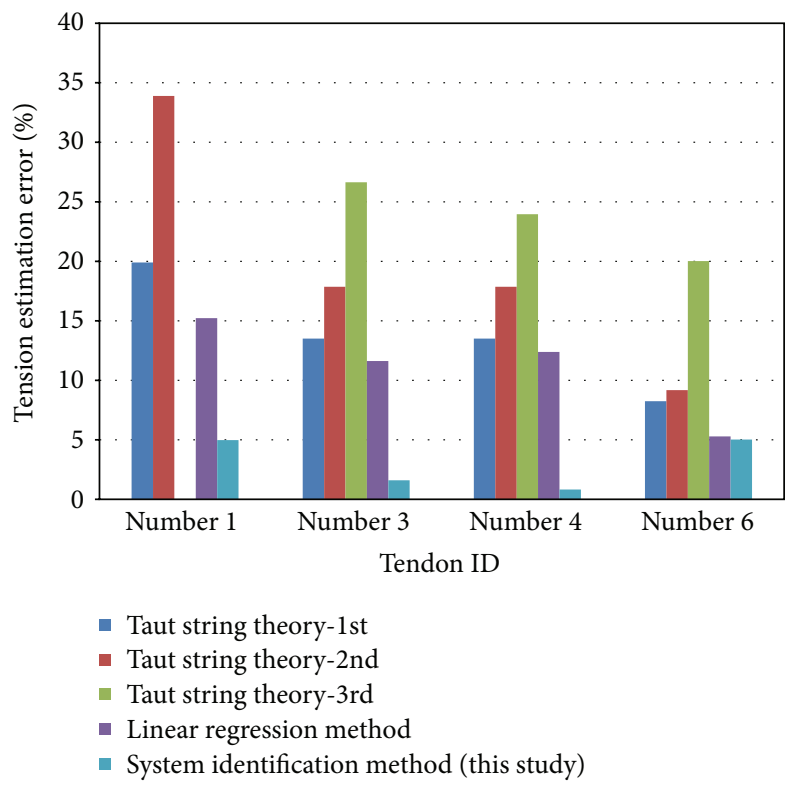

FIgURE 12: Tension estimation error (\%) of external tendon of Incheon Grand Bridge.

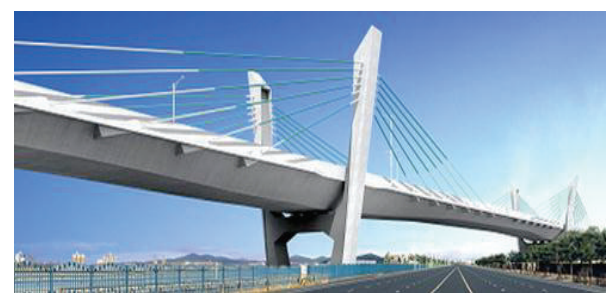

Figure 13: An overall view of Aam Bridge.

TABLE 10: Mean and standard deviation (\%) of tension estimation errors for extradosed cables.

\begin{tabular}{lcc}
\hline Method & Mean & Standard deviation \\
\hline $\begin{array}{l}\text { Taut string theory } \\
\text { Linear regression }\end{array}$ & 1.93 & 1.24 \\
$\begin{array}{l}\text { method } \\
\begin{array}{l}\text { System identification } \\
\text { method (this study) }\end{array}\end{array}$ & 1.08 & 0.54 \\
\hline
\end{tabular}

The cables used in Aam Bridge are relatively long in length, and the estimation results of their tension using the existing theories, as shown in Figure 15 and Table 10, show somewhat improved results compared to those of the system identification method. However, all methods showed tensile force estimation errors within a range of 5\%. Therefore, the system identification method is thought to be applicable to the field operations if field engineers assume a $\pm 5 \%$ error when estimating tensile force due to errors in the acceleration signal measurements, material properties, and geometrical variable errors, and other environmental errors that cannot be excluded theoretically, such as thermal influence.

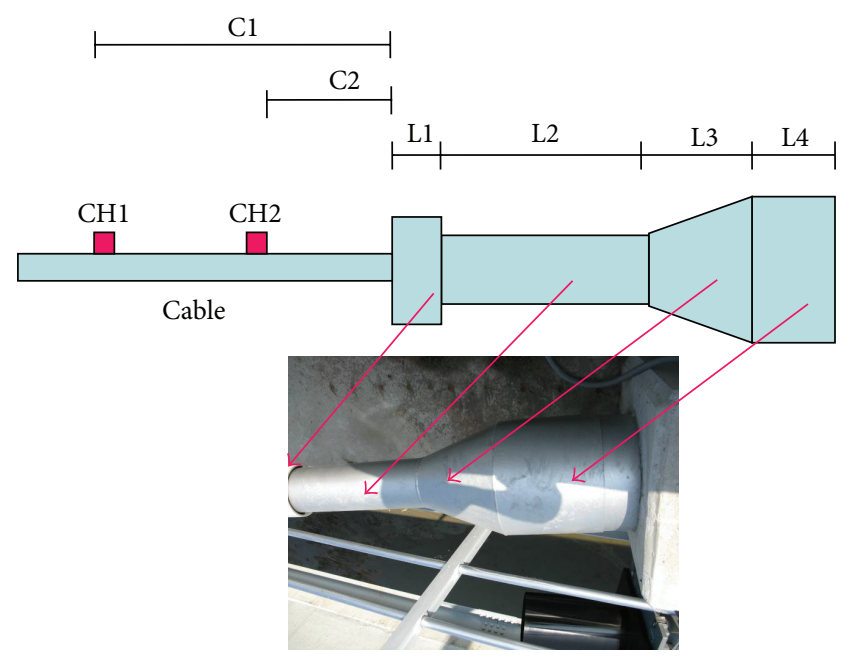

FIGURE 14: Vibration measurement set-up.

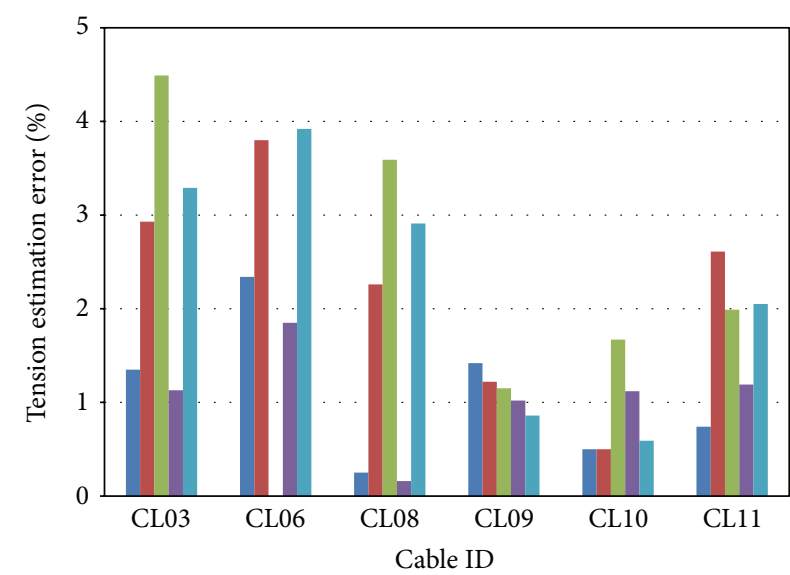

- Taut string theory-1st

- Taut string theory-2nd

- Taut string theory-3rd

- Linear regression method

- System identification method (this study)

Figure 15: Tension estimation error (\%) of Aam Bridge.

5.4. The Sigma Level Calculation of the Field Application Results. The statistical information (i.e., error of estimation method) is very important to field engineers. Therefore, as shown in Figures 16, 17, and 18, we performed sigma-level calculations for three field application results based on each tensile force estimation method to verify their reliabilities and applicability. In this case, the string theory and the linear regression methods differed in terms of their error level depending on the site, which did not satisfy the requirements for regularity. Therefore, the DPMO (Defect Per Million Opportunities) method was used for a short-term sigmalevel calculation. As for the system identification method, it satisfied the regularity requirement, and the $Z$-bench value was used to calculate the short-term sigma level. In all methods, a tensile force estimation error of $5 \%$ was set as the upper limit. 


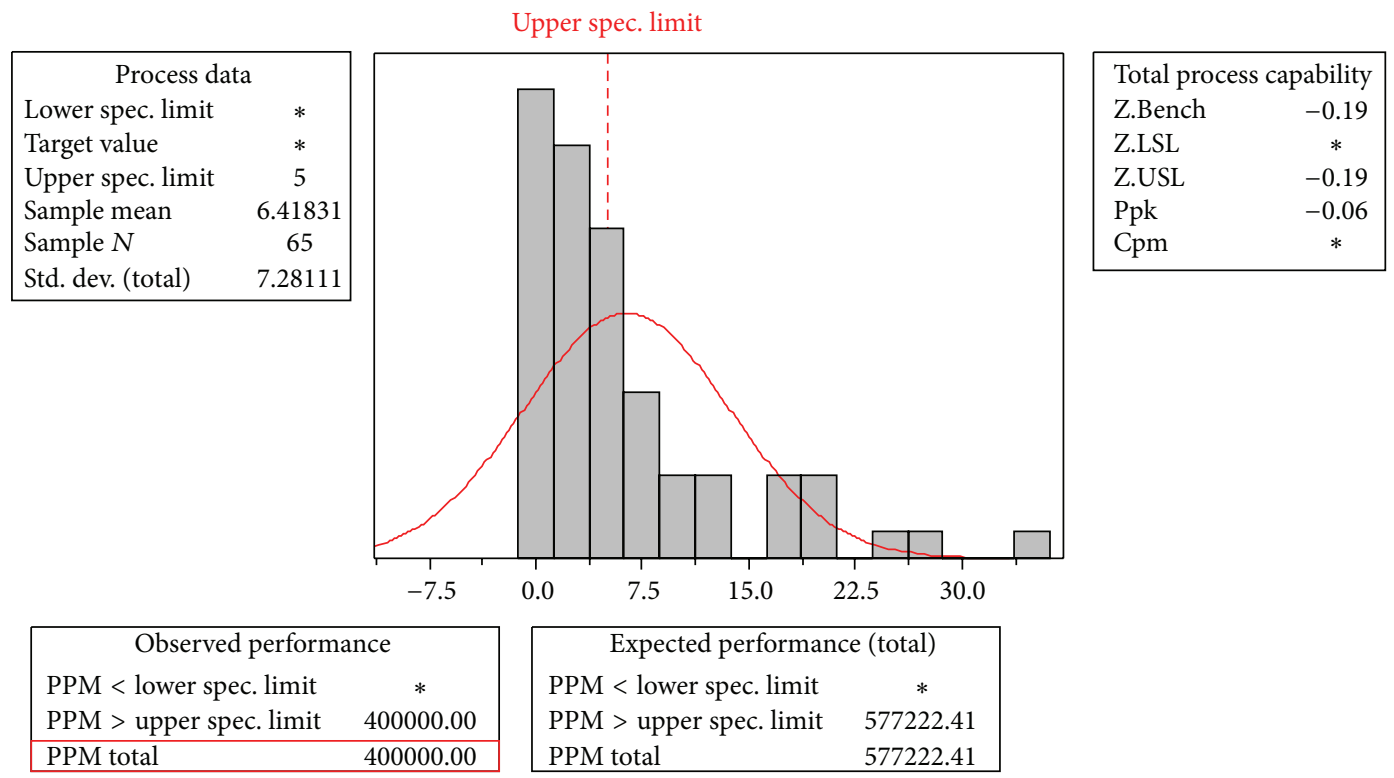

FIGURE 16: Process capability of field application error for the taut string theory.

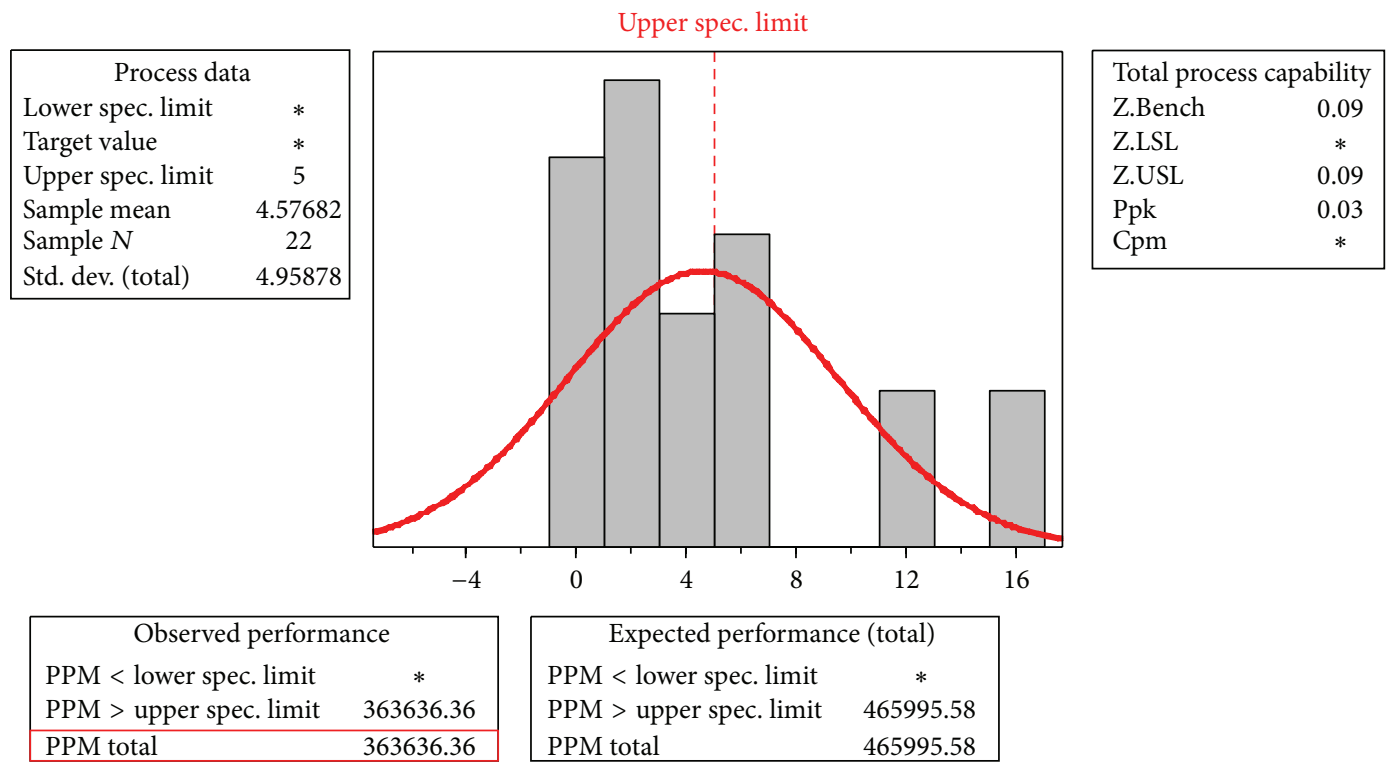

FIGURE 17: Process capability of field application error for the linear regression method.

As with Table 11, the system identification method was shown to be a better method than existing theories in terms of field applicability for external tendons of various types if the yield and short-term sigma level are compared.

\section{Conclusion}

This study used the system identification method for estimating the tensile force of external tendons to benchmark numerical examples, laboratory test samples, and field structure to get the following conclusion.
The string theory and the linear regression method are based on theoretical closed-form equations. For this reason, they showed an allowable level of errors in terms of estimating the tensile force for the field applications with the external tendons that had similar characteristics with the assumptions used in deriving the relationship equations between the natural frequencies and tensile forces (for Yeongdeok number 1 Bridge and Aam Bridge). However, they were not applicable for field applications as the errors were too large for the external tendons with different properties from those assumed, whereas the tension estimation method using the system 


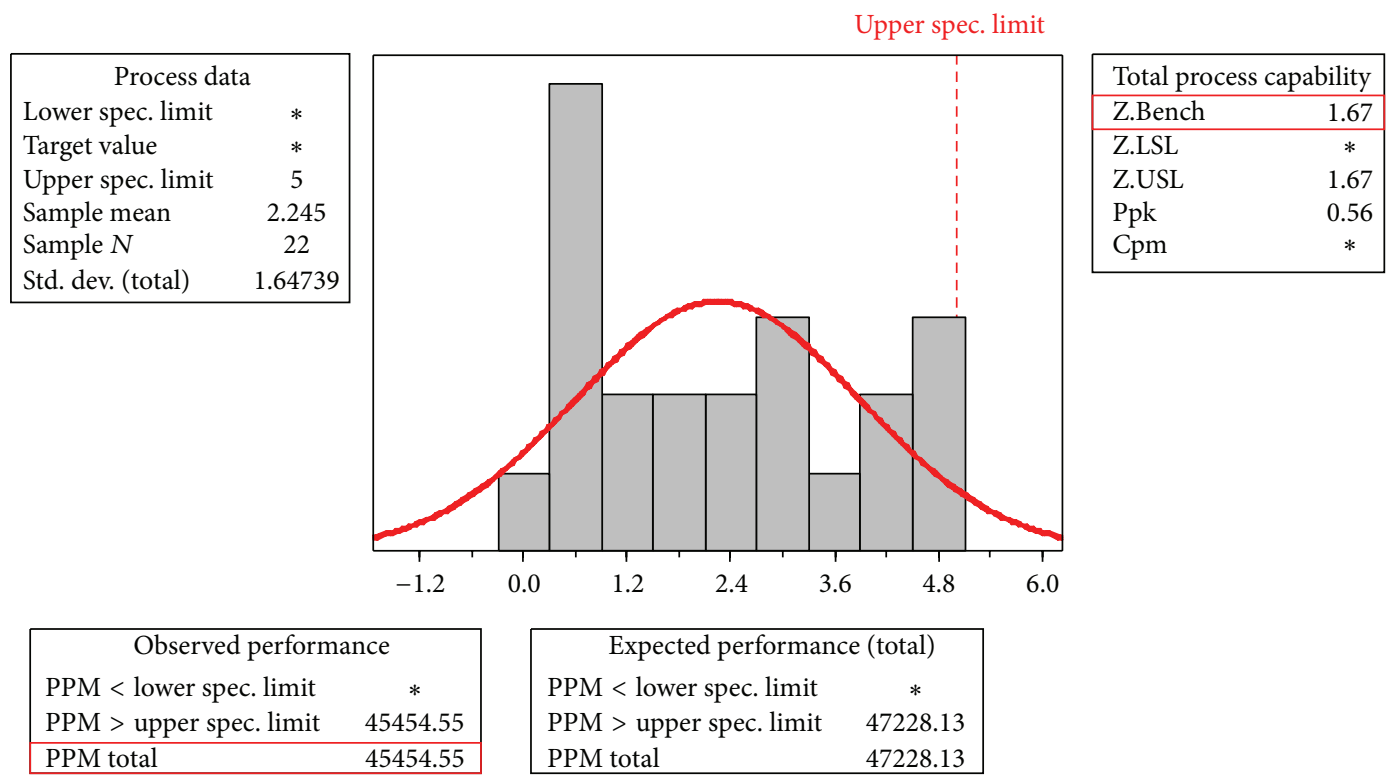

FIGURE 18: Process capability of field application error for the system identification method.

TABLE 11: Final yield and short-term sigma level.

\begin{tabular}{lccc}
\hline Method & DPMO/Z-bench & Yield (\%) & Short-term sigma level \\
\hline Taut string theory & 400,000 & 60.0 & 1.75 \\
Linear regression method & 363,636 & 63.6 & 1.85 \\
System identification method (this study) & 1.67 & 95.3 & 3.17 \\
\hline
\end{tabular}

identification technique was applicable not only to the external tendons to which the existing theories could be applied (Yeongdeok number 1 Bridge and Aam Bridge) but also to the external tendons to which they could not be applied (approach bridge section of Incheon Grand Bridge). This is because the development method was based on the finite element model. Also, the newly developed method could use the SRSS errors between the measurements of natural frequencies and their calculated results to determine the reliability of the estimated tensile force. Therefore, the tensile force estimation method using the system identification technique could be used efficiently to estimate the tensile forces of various types of external tendons.

\section{Conflict of Interests}

The authors declare that there is no conflict of interests regarding the publication of this paper.

\section{Acknowledgments}

This research was supported by the Construction Core Technology Program funded by the Ministry of Construction \& Transportation of the Korean government (Grant no. 2006D20). The financial support is gratefully acknowledged.

\section{References}

[1] H. M. Irvine, Cable Structures, The MIT Press, Cambridge, Mass, USA, 1981.
[2] H. Zui, T. Shinke, and Y. Namita, "Practical formulas for estimation of cable tension by vibration method," Journal of Structural Engineering, vol. 122, no. 6, pp. 651-656, 1996.

[3] W.-H. P. Yen, A. B. Mehrabi, and H. Tabatabai, "Evaluation of stay cable tension using a non-destructive vibration technique," in Proceedings of the 15th Structures Congress, pp. 503-507, ASCE, New York, NY, USA, April 1997.

[4] A. B. Mehrabi and H. Tabatabai, "Unified finite difference formulation for free vibration of cables," Journal of Structural Engineering, vol. 124, no. 11, pp. 1313-1322, 1998.

[5] T. Park and B. H. Kim, "Estimation of cable tension using system identification technique: I. theory," Journal of the Korean Society of Civil Engineers, vol. 25, no. 4A, pp. 661-668, 2005.

[6] T. Park, S. Moon, H. J. Joo, and B. H. Kim, "Estimating tensile force of hangers in suspension bridges using frequency based SI technique: I. Theory," Journal of the Korean Society of Civil Engineers, vol. 27, no. 2, pp. 165-172, 2007. 


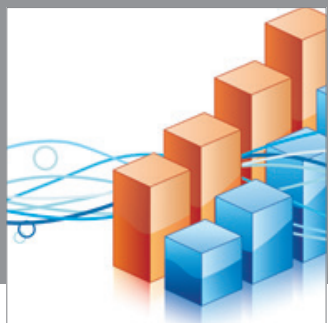

Advances in

Operations Research

mansans

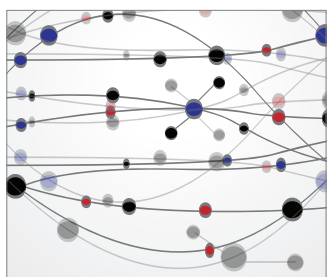

The Scientific World Journal
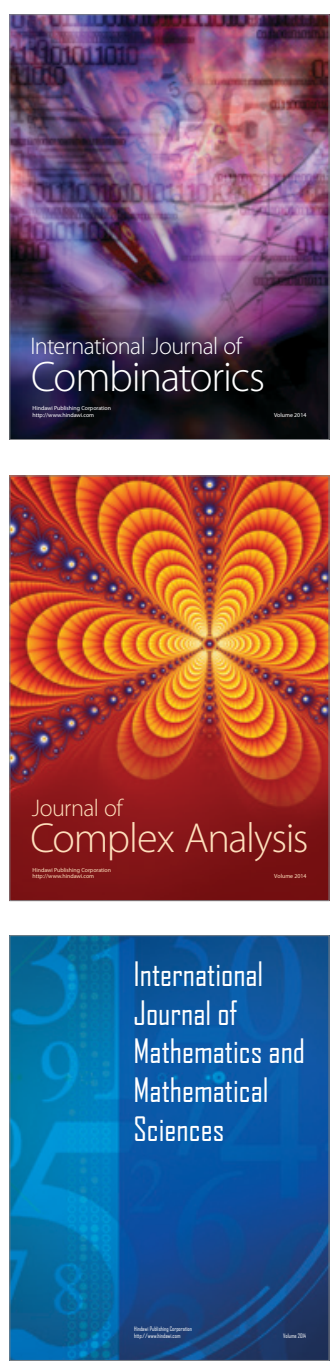
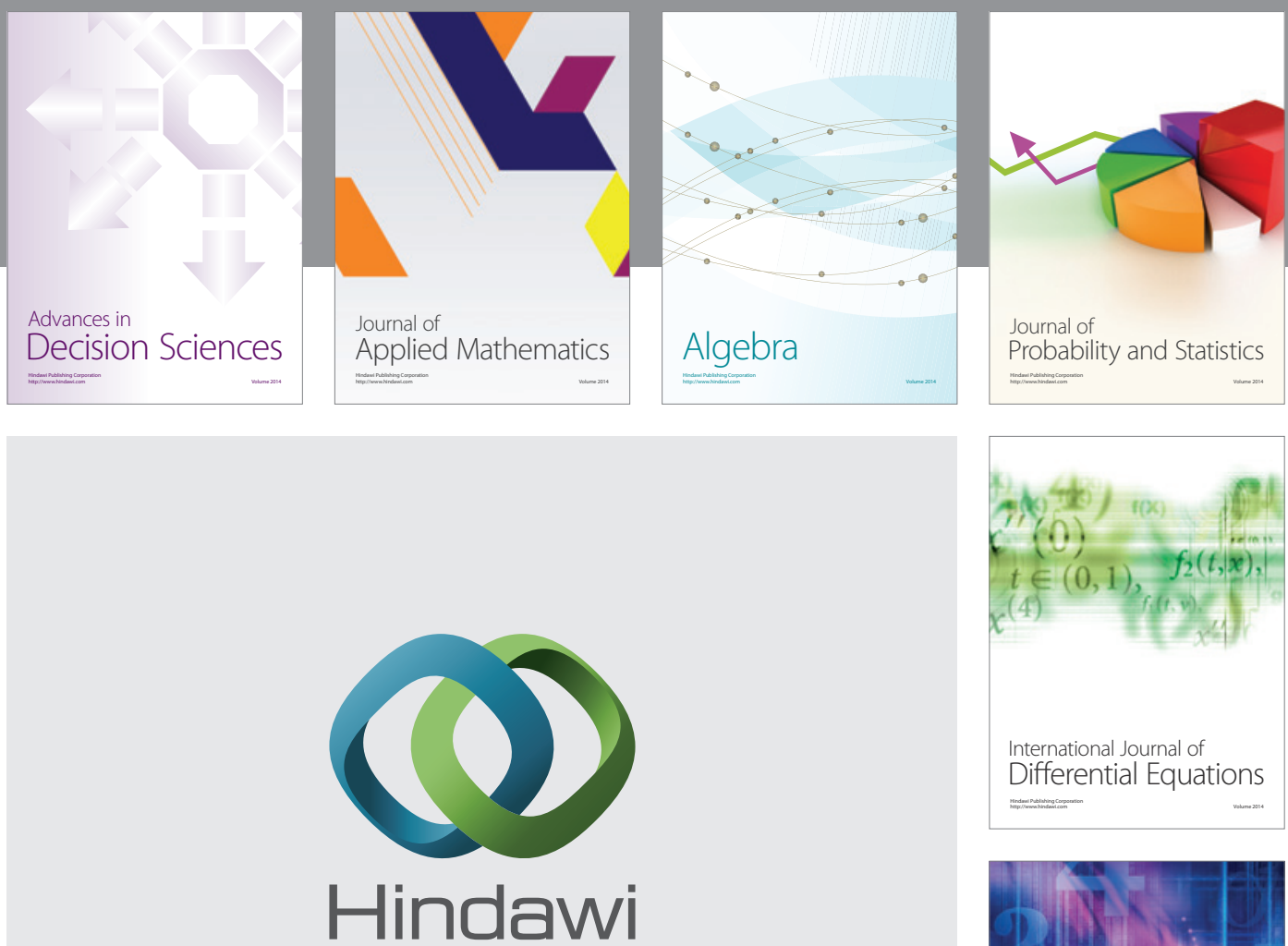

Submit your manuscripts at http://www.hindawi.com
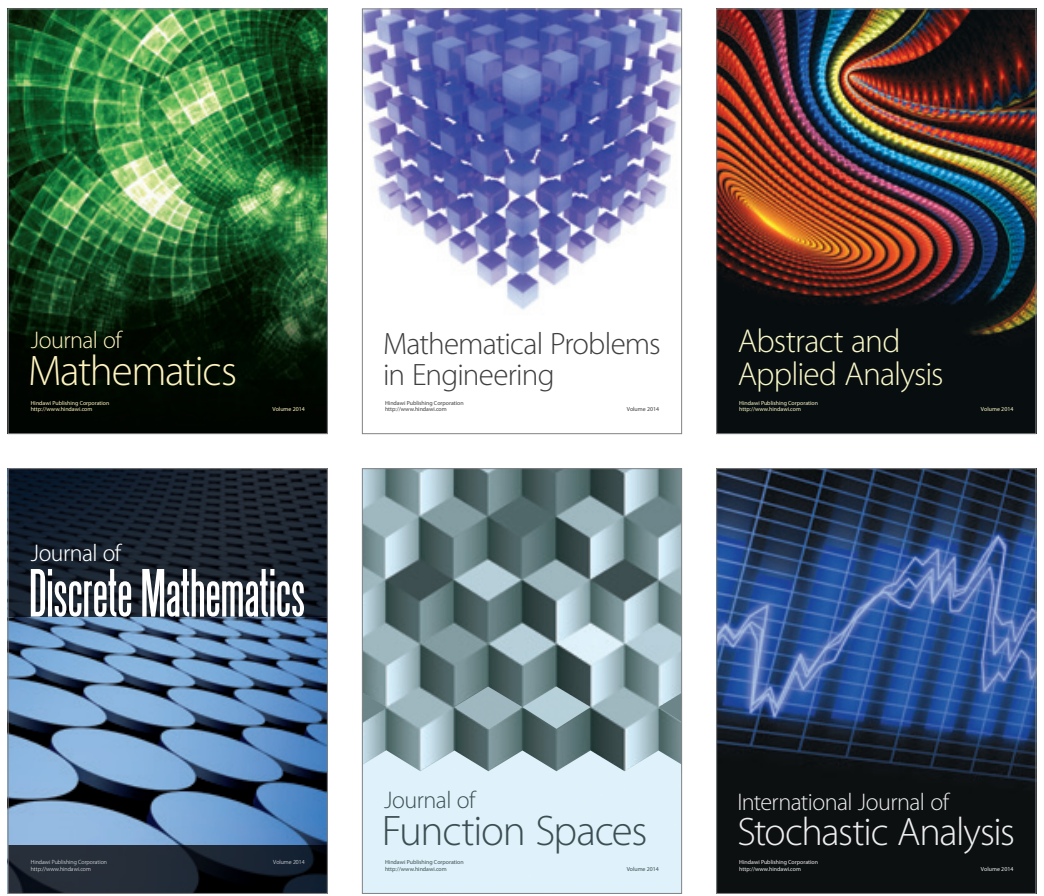

Journal of

Function Spaces

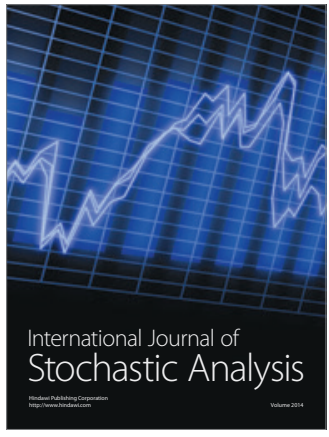

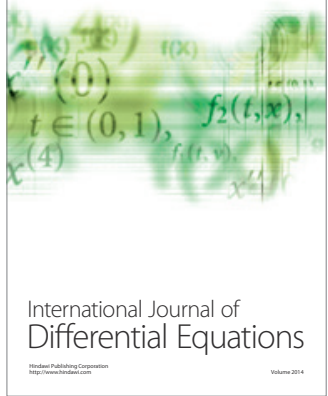
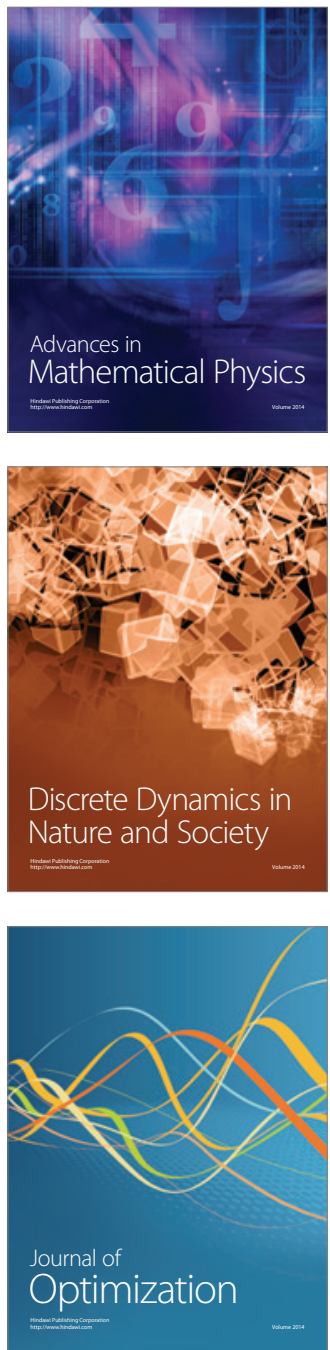